\title{
Hormonal status affects plasma exposure of tamoxifen and its main metabolites in tamoxifen-treated breast cancer patients
}

João Paulo Bianchi Ximenez ${ }^{1}$, Jurandyr Moreira de Andrade ${ }^{2}$, Maria Paula Marques ${ }^{1}$, Eduardo Barbosa Coelho ${ }^{3}$, Guilherme Suarez-Kurtz ${ }^{4}$ and Vera Lucia Lanchote ${ }^{1^{*}}$

From 2nd Latin American Congress of Clinical and Laboratorial Toxicology

Porto Alegre, Brazil. 3-6 June 2018

\begin{abstract}
Background: Tamoxifen is considered a prodrug of its active metabolite endoxifen, which is dependent on the CYP2D6 and CYP3A enzymes. Tamoxifen pharmacokinetic variability influences endoxifen exposure and, consequently, its clinical outcome. This study investigated the impact of hormonal status on the pharmacokinetics of tamoxifen and its metabolites in TAM-treated breast cancer patients.

Methods: TAM-treated breast cancer patients $(n=40)$ previously believed to have CYP3A activity within the normal range based on oral midazolam and phenotyped as CYP2D6 normal metabolizers using oral metoprolol were divided into two groups according to premenopausal ( $n=20$; aged $35-50$ years) or postmenopausal ( $n=20$; aged 60-79 years) status. All patients were treated with $20 \mathrm{mg} /$ day tamoxifen for at least three months. Serial plasma samples were collected within the $24 \mathrm{~h}$ dose interval for analysis of unchanged tamoxifen, endoxifen, 4hydroxytamoxifen and N-desmethyltamoxifen quantified by LC-MS/MS. CYP activities were assessed using midazolam apparent clearance (CYP3A) and the metoprolol/alfa-hydroxymetoprolol plasma metabolic ratio (CYP2D6). CYP3A4, CYP3A5 and CYP2D6 SNPs and copy number variation were investigated using TaqMan assays.

Results: Postmenopausal status increased steady-state plasma concentrations (Css) of tamoxifen (116.95 vs 201.23 $\mathrm{ng} / \mathrm{mL}$ ), endoxifen (8.01 vs $18.87 \mathrm{ng} / \mathrm{mL}$ ), N-desmethyltamoxifen (485.16 vs $843.88 \mathrm{ng} / \mathrm{mL}$ ) and 4-hydroxytamoxifen ( 2.67 vs $4.11 \mathrm{ng} / \mathrm{mL}$ ). The final regression models included hormonal status as the only predictor for Css of tamoxifen $[\beta$-coef $\pm S E, p$-value $(75.03 \pm 17.71, p=0.0001)]$ and 4 -hydroxytamoxifen $(1.7822 \pm 0.4385, p=0.0002)$, while endoxifen Css included hormonal status $(8.578 \pm 3.402, p=0.02)$ and race $(11.945 \pm 2.836, p=0.007)$. For $\mathrm{N}$ desmethyltamoxifen Css, the final model was correlated with hormonal status $(286.259 \pm 76.766, p=0.0007)$ and weight $(-8.585 \pm 3.060, p=0.008)$.
\end{abstract}

Conclusion: The premenopausal status was associated with decreased endoxifen plasma concentrations by $135 \%$ compared to postmenopausal status. Thus, the endoxifen plasma concentrations should be monitored mainly in the premenopausal period to maintain plasma levels above the efficacy threshold value.

Trial registration: $\mathrm{RBR}-7 \mathrm{tqc} 7 \mathrm{k}$.

Keywords: Tamoxifen, Endoxifen, Hormonal status, CYP2D6, CYP3A4/5, Breast Cancer

\footnotetext{
* Correspondence: lanchote@fcfrp.usp.br

${ }^{1}$ Department of Clinical Analysis, Toxicology and Food Science, School of

Pharmaceutical Sciences of Ribeirão Preto, University of São Paulo, Ribeirão

Preto, Brazil

Full list of author information is available at the end of the article
}

(c) The Author(s). 2019 Open Access This article is distributed under the terms of the Creative Commons Attribution 4.0 International License (http://creativecommons.org/licenses/by/4.0/), which permits unrestricted use, distribution, and reproduction in any medium, provided you give appropriate credit to the original author(s) and the source, provide a link to the Creative Commons license, and indicate if changes were made. The Creative Commons Public Domain Dedication waiver (http://creativecommons.org/publicdomain/zero/1.0/) applies to the data made available in this article, unless otherwise stated. 


\section{Background}

Tamoxifen (TAM) has been used for more than 40 years to treat early breast cancer and metastatic breast cancer in either preoperative or postoperative adjuvant therapy. A selective ER modulator, TAM is one of the most commonly used endocrine therapeutic agents for the treatment of estrogen receptor (ER)-positive breast carcinoma, acting as an estrogen antagonist or agonist depending on tissue type [1]. In adjuvant treatment, 5-year TAM therapy almost halves the annual risk of breast cancer recurrence and decreases the breast cancer mortality incidence by one-third in pre- and postmenopausal patients [2].

The TAM anticancer effect is due to its two active metabolites, 4-hydroxytamoxifen (4-HTAM) and endoxifen (END), which have a 100-fold higher antiestrogenic effect than the parent drug [3]. Once END plasma concentrations exceed 4-HTAM concentrations, END is considered the metabolite responsible for the clinical impact of TAM. Therefore, there is considerable concern regarding END exposure variability and consequently treatment outcome [4].

TAM is mainly converted by CYP3A4/5 to $\mathrm{N}$ desmethyltamoxifen (NDTAM), and it is subsequently converted to END by CYP2D6. As a minority pathway, TAM is oxidized by CYP2C9 and CYP2D6 to 4-HTAM, which is further converted to END by CYP3A4/5 $[5,6]$. TAM and its oxidized metabolites are further metabolized by phase II enzymes, such as sulfotransferases (SULTs) and UDP-glucuronosyltransferases UGTs [7].

The potential role of CYP2D6 genotype assessment in determining whether breast cancer patients should receive TAM is controversial. Multiple studies [8-11] have shown that the clinical outcome of adjuvant TAM is influenced by the CYP2D6 genotype since poor metabolizers (PMs) have a higher risk of breast cancer recurrence than normal metabolizers (NMs). However, other clinical trials, including the ATAC [12], BIG1-98 [13] and ABCSG8 [14] trials, have shown conflicting data from 5-year TAM prospective analysis regarding the association between CYP2D6 genotype and clinical outcome.

Based on current evidence [1], CYP2D6 NMs and ultrarapid metabolizers (UMs) are expected to achieve therapeutic END plasma concentrations following administration of TAM at $20 \mathrm{mg} /$ day standard doses. For CYP2D6 intermediate metabolizers (IMs) and PMs, 40 mg/day TAM can be considered or alternative therapy, such as an aromatase inhibitor (AI) for postmenopausal women or AI along with ovarian function suppression in premenopausal women [1].

Regarding the role of measurement of END concentrations, lower END concentrations were shown to be associated with poor clinical outcome in a mixed cohort of pre- and postmenopausal [4] patients and in a study of only premenopausal patients [15]. Notably, an in vitro study showed that END could block breast cancer cell growth in the presence of a high estrogen concentration that mimics premenopausal patients [16].

In addition to the pharmacogenetic effect, there has been speculation regarding the association between menopausal status and TAM treatment outcome. Since the metabolism of drugs is associated with hormonal status [17-20], plasma concentrations of TAM active metabolites could be influenced by the menopausal status of the women.

In postmenopausal women, TAM and its metabolites occupy most of the available ERs, suggesting that variation in END plasma concentration would have a small effect in blocking these receptors [21]. However, END may be critical to saturate the ERs in premenopausal women, in whom TAM and its metabolites are estimated to occupy only $90-95 \%$ of the available receptors [21].

The current scenario points to the need for combined pharmacokinetic and pharmacogenetic analyses in both pre- and postmenopausal patients since many of the studies have reported results from only one hormonal status group. This study investigates the influence of menopausal status on the pharmacokinetics of TAM and its metabolites END, 4-HTAM and NDTAM in TAM-treated breast cancer patients phenotyped as NMs for CYP2D6 and with CYP3A activity based on the oral midazolam clearance.

\section{Methods}

\section{Patients and data collection}

A total of 40 TAM-treated breast cancer patients (20 $\mathrm{mg}$ /day) were recruited, and they were distributed into 2 groups according to age and menopausal status $(n=20 /$ group): A) premenopausal (patients aged $<50$ years) and B) postmenopausal (patients aged $>60$ years) groups. All patients were histologically diagnosed with ER-positive breast cancer, and the clinical diagnosis of menopause was based on menstrual history, ultrasound features (ovarian volume) and age. Patients were suitable for inclusion if they were not concomitantly taking moderate or potent inhibitors or inducers of CYP3A and the drug transporter ABCB1 (P-glycoprotein) or inhibitors of CYP2D6. The study was approved by the ethics review committees of the School of Pharmaceutical Sciences of Ribeirão Preto, University of São Paulo, SP, Brazil and of the Teaching Hospital of Ribeirão Preto Medical School, University of São Paulo, SP, Brazil (record number: 35539714.7.0000.5403). All patients provided written consent.

TAM pharmacokinetics and metabolism were evaluated after at least three months of drug treatment, at steady-state, during a $24 \mathrm{~h}$ dosing interval. Blood samples $(1 \mathrm{~mL})$ were collected predosing and $30 \mathrm{~min}$ and 1 , $1.5,2,3,4,6,8,12,16$ and $24 \mathrm{~h}$ after the administration of the daily TAM dose. Twenty-four hours after the end 
of the TAM study, metoprolol $(100 \mathrm{mg})$ and midazolam $(15 \mathrm{mg})$ were orally administered as a single dose, and blood samples $(4 \mathrm{~mL})$ were collected predosing and 15 and $30 \mathrm{~min}$ and 1, 2, 3, 4, 5 and $6 \mathrm{~h}$ after drug administration. For pharmacogenetic screening, whole blood (2 $\mathrm{mL}$ ) was collected in EDTA tubes and stored at $-70{ }^{\circ} \mathrm{C}$ until analysis.

\section{TAM and its metabolites measurement in plasma}

Plasma samples of $200 \mu \mathrm{L}$ were added with the internal standard solution (mexiletine, $5 \mu \mathrm{g} / \mathrm{mL}$ ), $25 \mu \mathrm{L}$ of $1 \mathrm{M}$ sodium hydroxide aqueous solution and $2 \mathrm{~mL}$ methyl tert-butyl ether. TAM, NDTAM, 4-HTAM and END were resolved on an RP-Select B LiChroCART ${ }^{\bullet}$ C18 column using as a mobile phase a mixture of $10 \mathrm{mM}$ ammonium formate and acetonitrile (1:1, v:v) added with $0.1 \%$ formic acid. TAM and its metabolites were quantified by Quattro Micro LC triple-quadrupole mass spectrometry (Waters, Milford, EUA) in the positive ion electrospray ionization mode as described previously with some modifications [22]. The method had no matrix effect and showed linearities for TAM and END in the range of 1$1250 \mathrm{ng} / \mathrm{mL}$, for 4 -HTAM of $0.4-500 \mathrm{ng} / \mathrm{mL}$ and for NDTAM of $2-2500 \mathrm{ng} / \mathrm{mL}$ of plasma. The coefficients of variation and the relative standard errors of the accuracy and precision studies were less than $15 \%$.

\section{CYP2D6 phenotype}

Aliquots of $100 \mu \mathrm{L}$ of plasma supplemented with tramadol as an internal standard $(50 \mu \mathrm{g} / \mathrm{ml}), 25 \mu \mathrm{L}$ of $1 \mathrm{M}$ sodium hydroxide aqueous solution, $10 \mathrm{mg}$ of sodium chloride and $2 \mathrm{~mL}$ of dichloromethane-diisopropyl ether $(1: 1, v / v)$. The compounds were separated on an RP Select B column (LiChrospher ${ }^{\circ} 60$ Merck, Darmstadt, Germany) using buffer phosphate $(0.05 \mathrm{M}$ and $\mathrm{pH} 3.5)$ and acetonitrile $(90: 10, \mathrm{v} / \mathrm{v})$ as the mobile phase and analyzed using a fluorescence detector (229 and $298 \mathrm{~nm}$ ) $[23,24]$. Calibration curves were constructed from 20 to $1000 \mathrm{ng}$ metoprolol/mL and from 10 to $500 \mathrm{ng} \alpha-$ hydroxymetoprolol/mL. Accuracy and precision studies showed coefficients of variation and relative standard errors less than $15 \%$.

\section{CYP3A4 in vivo activity}

Aliquots of $1 \mathrm{~mL}$ plasma supplemented with clobazam $(2.5 \mathrm{ng})$ as an internal standard were extracted with toluene-isoamyl alcohol (100:0.1, v/v). The compounds were separated on a Purospher RP 18e column (MerckKGaA, Darmstadt, Germany) using acetonitrile:10 mmol/L ammonium acetate aqueous solution $(1: 1, \mathrm{v} / \mathrm{v})$ as the mobile phase and quantified by Quattro Micro LC triplequadrupole mass spectrometry (Waters, Milford, USA) in the positive ion electrospray ionization mode [25]. Calibration curves were constructed from 0.1 to $50 \mathrm{ng} / \mathrm{mL}$ plasma. The method showed coefficients of variation and relative standard errors less than $15 \%$, respectively, in the studies of precision and accuracy.

\section{Genotyping}

DNA was obtained from peripheral blood leukocytes according to usual procedures with a QIAamp DNA Blood Mini Kit (Qiagen, Hilden, GER) according to the manufacturer's instructions.

The following SNPs were detected by real-time polymerase chain reaction with 5 -nuclease allelic discrimination assays according to the manufacturer's instructions: CYP2D6 -1584C > G (rs1080985), 31G > A (rs769258), 100C > T (rs1065852), 1023C > T (rs28371706), 1846G > A (rs3892097), 2549A > del (rs35742686), 2615 2617delAAG (rs28371720), 2850C > T (rs16947), 2988G > A (rs28371725), 3183G > A (rs59421388), 4180G > C (rs1135840), CYP3A4*1B (rs2740574), CYP3A4*22 (rs35599367), and CYP3A5*3 (rs776746). Gene deletion (CYP2D6*5, Hs00010001_cn) and duplication/multiplication $(\mathrm{CYP} 2 \mathrm{D} 6 \% \mathrm{xN})$ were analyzed by TaqMan copy number assay.

\section{Pharmacokinetic analyses}

Pharmacokinetic analyses of TAM and its metabolites were performed as a non-compartmental model using WinNonlin 4.4 (Pharsight Corporation, Mountain View, CA, USA). The observed maximum plasma concentration (Cmax) and the time to reach the Cmax (Tmax) were obtained by visual inspection of the experimental data. The area under the plasma concentration-time curve from time zero to $24 \mathrm{~h}$ (AUCT) was calculated using linear trapezoidal rule. The concentration in the steady state (Css) was calculated by dividing the AUCT by $\tau$, where $\tau$ is the dosing interval. The metabolic ratio (MR) was defined as the ratio of AUCt parent drug to AUCi metabolite drug.

The metoprolol oxidation capacity was expressed according to the $\log 10$ metoprolol/ $\alpha$-hydroxymetoprolol plasma ratio (metabolic ratio - MR). Poor metabolizers (PM) were identified in situations where log10 metoprolol/ $\alpha$-hydroxymetoprolol plasma ratios were $\geq 1.5$ [23]

CYP3A activity was estimated by the apparent clearance (CL/F) of midazolam evaluated by the software WinNonlin 4.4., corrected for body weight and expressed as $\mathrm{mL}$ $\mathrm{min}^{-1} \mathrm{~kg}^{-1}$, according to the Lamba et al. (2002) [26].

\section{Statistical analyses}

Based on a previous study reported by Etienne et al., 1989 [27], twenty patients in each group (pre- and postmenopausal) were estimated to be adequate to detect a $30 \%$ change in the AUC of TAM between the two study groups, with a power of at least $80 \%$ and alpha level of $5 \%$. 
Age (years), weight, BMI, log of MR (metoprolol/ $\alpha$ hydroxymetoprolol), apparent midazolam clearance, AUCt, $\mathrm{C}_{\mathrm{SS}}$ and MR of TAM and its metabolites were analyzed as continuous variables; hormonal status (pre- and postmenopausal), race (white or non-white), CYP2D6 (NM, IM, and others), CYP3A5*3 (expressors and nonexpressors), CYP3A4*22 (carriers and non-carriers) and CYP3A4*1B (carriers and non-carriers) were analyzed as categorical variables.

CYP2D6 diplotypes were inferred using HaploStats software (version 1.7.7) implemented on the $\mathrm{R}$ platform. Software-generated haplotypes were compared to the CYP Allele Nomenclature Database for the star (*) allele designation. Haplotypes not matched with known CYP2D6 alleles were grouped into the "other" category [28]. The activity score (AS) system was used to define the perceived functionality of the CYP2D6 diplotypes. Values of 0-2 were attached to the alleles identified in the study cohort as follows: zero, no-function alleles $(* 4, * 4 \mathrm{xN}, * 5)$; 0.5, decreased-function alleles $(* 9, * 10, * 17, * 29, * 41) ; 1$, normal-function alleles $(* 1, * 2, * 39)$ and 2 , increasedfunction alleles $\left({ }^{*} 1 \mathrm{xN},{ }^{*} 2 \mathrm{xN}\right)$. The AS of diplotypes resulted from the sum of the assigned value to each allele. Patients with $\mathrm{AS}=0, \mathrm{AS}=0.5$, and $\mathrm{AS}>2$ were designated genetic PM, IM, and UM, respectively. Patients with AS = $1, \mathrm{AS}=1.5$, and $\mathrm{AS}=2$ were designated $\mathrm{NM}[29,30]$.

First, descriptive statistics were run to describe the general characteristics of the participants. Then, AUCT, $\mathrm{C}_{\mathrm{SS}}$ and MR of TAM and its metabolites were compared among the categorical variables by t-test. Subsequently, Spearman correlation rank tests were used to examine the correlations among TAM and its metabolites AUCT, $\mathrm{C}_{\mathrm{SS}}$ and $\mathrm{MR}$ with genotype, phenotype and demographic variables. Finally, multiple regression modeling was used to assess the effect of genotypes, phenotypes and demographic variables on the Css of TAM and its metabolites. The genotype frequencies of the CYP2D6, CYP $3 A 5 * 3$,
CYP3A4*22 and CYP3A4*1B polymorphisms were derived by gene counting. Deviations from Hardy-Weinberg equilibrium were assessed by the chi-square test. The statistical analyses were performed with RStudio version 1.1.456 (RStudio, Boston, MA), and all tests considered $p<0.05$ statistically significant.

\section{Results \\ Study data}

The data for pharmacokinetics analysis consisted of 480 samples collected from 40 TAM-treated breast cancer patients distributed into two groups according to age and menopausal status. The characteristics of the patients are shown in Table 1. The cohort study showed a geometric mean age of 45.3 years and a body mass index (BMI) of 29.58 for the premenopausal group $(n=20)$. For the postmenopausal group $(n=20)$, the geometric mean of age was 66.8 years, and BMI was 28.07.

\section{Influence of hormonal status on the pharmacokinetics of tamoxifen and its metabolites}

The mean plasma concentration-time profiles for TAM and its metabolites END, 4-HTAM and NDTAM in all investigated $(n=40)$ TAM-treated breast cancer patients given $20 \mathrm{mg}$ daily are shown in Fig. 1. The fluctuation values at steady state, calculated as the ratio $\left(C_{\max }-C_{\min }\right) / C_{\min }$ and expressed as the geometric mean and 95\% CI, were 206\% (176-235) for TAM, 156\% (148-164) for NDTAM, 127\% (116-138) for 4-HTAM and 154\% (139-169) for END.

The pharmacokinetic parameters of TAM and its metabolites, evaluated at steady state, are summarized in Table 2 and Fig. 2 according to hormonal status, which was defined as premenopausal $(n=20)$ or postmenopausal $(n=20)$. The metabolic ratios $(M R)$ did not differ between groups $(p>0.05)$, with values of

Table 1 Baseline demographics and phenotypes in the investigated TAM-treated breast cancer patients $(n=40)$. Data are reported as the mean and $95 \% \mathrm{Cl}$ or percent

\begin{tabular}{|c|c|c|}
\hline & $\begin{array}{l}\text { Pre-menopausal } \\
(n=20)\end{array}$ & $\begin{array}{l}\text { Post-menopausal } \\
(n=20)\end{array}$ \\
\hline Age at diagnosis (years) & $45.3(44.70-45.90)$ & $66.8(66.13-67.46)$ \\
\hline $\mathrm{BMI}\left(\mathrm{kg} / \mathrm{m}^{2}\right)$ & $29.58(28.90-30.25)$ & $28.07(27.58-28.56)$ \\
\hline Color (\%) & white (85), non-white (15) & white (75), non-white (25) \\
\hline Cancer type (\%) & $\begin{array}{l}\text { ductal in situ (5), invasive ductal (90) and } \\
\text { invasive lobular (5) }\end{array}$ & $\begin{array}{l}\text { ductal in situ (0), invasive ductal (90) and } \\
\text { invasive lobular (10) }\end{array}$ \\
\hline HER2 status (\%) & positive (20), negative (75) and unknown (5) & positive (10), negative (80) and unknown (10) \\
\hline Chemotherapy (\%) & Yes (20) and No (80) & Yes (5) and No (95) \\
\hline CYP2D6 phenotype (MR) & $0.25(0.21-0.30)$ & $0.24(0.19-0.29)$ \\
\hline Midazolam oral clearance (mL/min/kg) & $30.09(21.55-42.02)$ & $24.10(19.41-29.92)$ \\
\hline
\end{tabular}




\section{TAM}

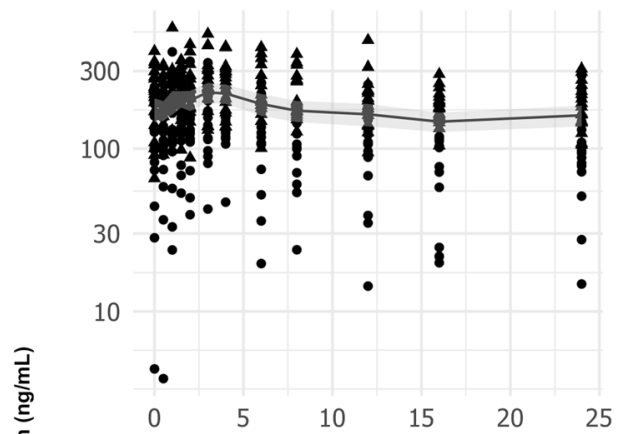

4HTAM

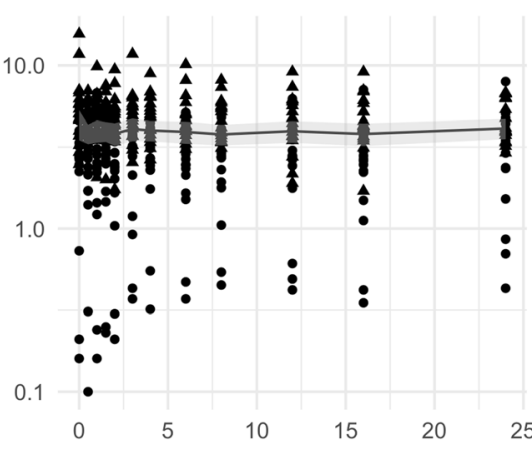

NDTAM

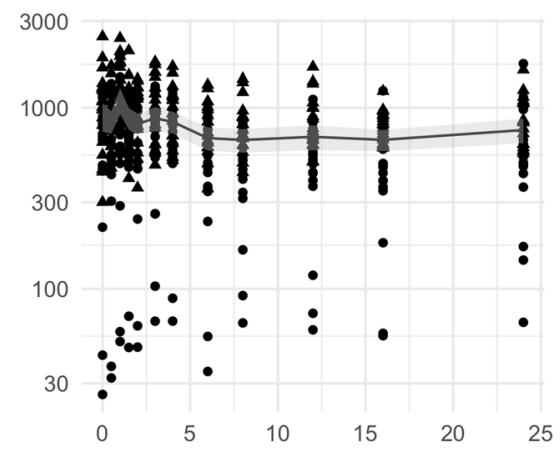

END

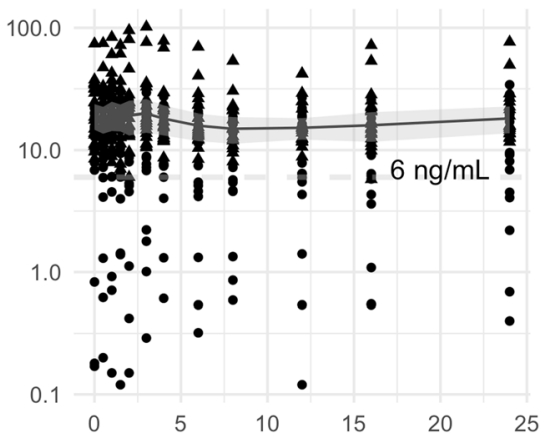

Time (h)

Mean \& CI 95\% Groups - Premenopausal ^ Postmenopausal

Fig. 1 Plasma concentration versus time of TAM and NDTAM (upper panels) and 4-HTAM and END (lower panels) observed during a dosing interval of TAM therapy ( $20 \mathrm{mg} /$ day) in all investigated TAM-treated breast cancer patients $(n=40)$. The value of 6 ng/ml END corresponds to the threshold associated with efficacy

TAM to NDTAM of approximately 0.20 , while NDTAM to END was higher than 40. However, the hormonal status increased the steady-state plasma concentration $\left(\mathrm{C}_{\mathrm{SS}}\right)$ of TAM and its metabolites NDTAM and 4 -HTAM by $70-80 \%$, whereas END was increased by $135 \%$ (Table 2).

\section{Effect of CYP2D6 and CYP3A phenotypes on the} disposition of tamoxifen and its metabolites

All 40 investigated TAM-treated breast cancer patients were classified as normal metabolizers (NM) for CYP2D6 activity based on the ratio log metoprolol/ hydroxymetoprolol concentrations in plasma at $3 \mathrm{~h}>1.5$ (23). The $\log$ metoprolol/hydroxymetoprolol ratios in plasma ( 0.25 versus 0.24 ; Table 1$)$ did not differ significantly across the two study groups (t-test, $p=0.7803$ ).

The oral midazolam clearance varied 22 -fold in all investigated patients $(8.26-180.82 \mathrm{~mL} / \mathrm{min} / \mathrm{kg})$. The oral midazolam clearance values were within the 10
$40 \mathrm{~mL} / \mathrm{min} / \mathrm{kg}$ range for 29 patients (72\%), below 10 $\mathrm{mL} / \mathrm{min} / \mathrm{kg}$ for one patient and higher than $40 \mathrm{~mL} /$ $\mathrm{min} / \mathrm{kg}$ for ten patients. The t-test revealed no significant differences in the midazolam CL/F (30.09 versus $24.10 \mathrm{~mL} / \mathrm{min} / \mathrm{kg}$; Table 1) across the two study groups (t-test, $p=0.1499$ ).

\section{Association of CYP2D6, CYP3A4 and CYP3A5} polymorphisms on the plasma concentrations of TAM and its metabolites

The activity scores of the allelic frequencies of CYP3A4, CYP3A5 and CYP2D6 are shown in Table 3. No patients had a PM or UM CYP2D6 phenotype. All investigated patients were CYP3A4*1 carriers. Twenty-seven patients were CY3A5 non-expressors (*3/*3), while thirteen were genotyped as CY3A5 expressors ("1/*1 and *1/*3). Significant correlations between the polymorphic variants in CYP3A4, CYP3A5, and CYP2D6 and TAM pharmacokinetics were not found. 
Table 2 Effect of hormonal status on the TAM pharmacokinetics and its metabolites END, 4-HTAM and NDTAM in the investigated TAM-treated breast cancer patients $(n=40)$. Data are reported as the geometric mean $(95 \% \mathrm{Cl})$

\begin{tabular}{|c|c|c|c|c|c|c|c|}
\hline \multirow{3}{*}{$\frac{\mathrm{AUCT}\left(\mathrm{ng} \mathrm{g}^{*} \mathrm{~h} / \mathrm{mL}\right)}{\mathrm{TAM}}$} & \multicolumn{3}{|c|}{ Premenopausal $(n=20)$} & \multicolumn{3}{|c|}{ Postmenopausal $(n=20)$} & \multirow{3}{*}{$\frac{P \text {-value }}{<0.001}$} \\
\hline & \multirow{2}{*}{$\frac{\text { Geometric Mean }}{2806.78}$} & \multicolumn{2}{|l|}{$95 \% \mathrm{Cl}$} & \multirow{2}{*}{$\begin{array}{l}\text { Geometric Mean } \\
4829.41\end{array}$} & \multicolumn{2}{|l|}{$95 \% \mathrm{Cl}$} & \\
\hline & & 2128.19 & 3701.75 & & 4244.20 & 5495.30 & \\
\hline NDTAM & $11,643.86$ & 8132.88 & $16,670.55$ & $20,253.09$ & $17,886.43$ & $22,932.88$ & $<0.010$ \\
\hline 4-HTAM & 61.67 & 44.15 & 86.15 & 112.23 & 98.75 & 127.55 & $<0.001$ \\
\hline END & 192.14 & 111.75 & 330.35 & 452.77 & 355.65 & 576.40 & 0.013 \\
\hline \multicolumn{8}{|l|}{ Css (ng/mL) } \\
\hline TAM & 116.95 & 88.67 & 154.24 & 201.23 & 176.84 & 228.97 & $<0.001$ \\
\hline NDTAM & 485.16 & 338.87 & 694.61 & 843.88 & 745.27 & 955.54 & $<0.010$ \\
\hline 4-HTAM & 2.57 & 1.84 & 3.59 & 4.68 & 4.11 & 5.31 & $<0.001$ \\
\hline END & 8.01 & 4.66 & 13.76 & 18.87 & 14.82 & 24.02 & 0.013 \\
\hline \multicolumn{8}{|l|}{ Metabolic Ratios } \\
\hline TAM/NDTAM & 0.20 & 0.15 & 0.26 & 0.21 & 0.19 & 0.23 & 0.523 \\
\hline TAM/4-HTAM & 46.27 & 36.67 & 58.39 & 38.12 & 31.79 & 45.70 & 0.177 \\
\hline NDTAM/END & 68.98 & 46.26 & 102.86 & 44.35 & 32.78 & 60.01 & 0.230 \\
\hline 4-HTAM/END & 0.30 & 0.20 & 0.44 & 0.24 & 0.19 & 0.31 & 0.275 \\
\hline \multicolumn{8}{|c|}{ Apparent clearance $(\mathrm{L} / \mathrm{h})$} \\
\hline TAM & 7.13 & 5.40 & 9.40 & 4.14 & 3.64 & 4.71 & 0.015 \\
\hline
\end{tabular}

Tamoxifen (TAM), endoxifen (END), 4-hydroxytamoxifen (4-HTAM) and N-desmethyl tamoxifen (NDTAM)

\section{Multiple regression analysis}

Multiple regression modeling was applied to carry out hormonal status-stratified analyses for the premenopausal $(n=20)$ and postmenopausal $(n=20)$ groups. Initially, we assessed whether the AUC $\tau$ and Css mean of TAM and its metabolites differed between the groups based on demographic, phenotype, and genotype variables by univariate analysis. Variables were included in the multiple regression modeling if they had a $p$-value lower than 0.15 in the t-test. The final multiple regression modeling included the hormonal status as the only predictor for Css of TAM $\left[\beta\right.$-coef \pm SE, p-value, $\mathrm{R}^{2}$ $\left.\left(75.03 \pm 17.71, \quad p=0.0001, \quad \mathrm{R}^{2}=0.33\right)\right]$ and 4-HTAM $\left(1.7822 \pm 0.4385, p=0.0002, R^{2}=0.31\right)$, while for END, Css included hormonal status $(8.578 \pm 3.402, p=0.02$, $\left.\mathrm{R}^{2}=0.32\right)$ and race $\left(11.945 \pm 2.836, p=0.007, \mathrm{R}^{2}=0.32\right)$ as predictors. For the Css of NDTAM, the final multiple regression modeling included hormonal status (286.259 \pm 76.766, $\left.p=0.0007, \mathrm{R}^{2}=0.37\right)$ and weight $(-8.585 \pm 3.060$, $\left.p=0.008, \mathrm{R}^{2}=0.37\right)$ as predictors.

\section{Discussion}

The effect of menopausal status on the pharmacokinetics of drugs has been poorly investigated. This is the first study showing the influence of hormonal status on the pharmacokinetics of TAM and its metabolites END, 4HTAM and NDTAM in pre- and postmenopausal TAMtreated breast cancer patients previously phenotyped as
NMs for CYP2D6 and with in vivo CYP3A activity based on midazolam oral clearance [23-25].

In the present study, serial blood samples $(n=12)$ were collected within the dosing interval of $24 \mathrm{~h}$ to evaluate the extent of fluctuation in the steady state of TAM and its metabolites. Although the half-lives of TAM and END are prolonged ( $>2$ days), the data presented in Fig. 1 show that the fluctuation at steady state ranged from 150 to $200 \%$ for TAM and its metabolites. Then, the $C_{s s}$ values reported in the present study were calculated as AUCt/dose interval and not as a plasma concentration collected at only one point within the dosing interval of $24 \mathrm{~h}$. The observed variability in the extent of fluctuation at the steady state of TAM and its metabolites, particularly END, is not only due to genetic factors in CYP enzymes and drug transporter P-gp but also to the simultaneous presence of multiple factors such as race and BMI [5, 31-33].

TAM pharmacokinetics were evaluated in premenopausal patients $(n=20)$ aged 35 to 50 years and in postmenopausal patients $(n=20)$ aged 60 to 79 years (Table 1). The premenopausal patients had a decrease of $135 \%$ in the Css of END and 70-80\% in the Css of TAM and its metabolites NDTAM and 4-HTAM (Table 2). These findings are consistent with Lien et al. (1995) [34], who also demonstrated that $\mathrm{N}$-desdimethyltamoxifen exposure was higher in postmenopausal women than premenopausal women, whereas only a tendency was observed for NDTAM. 


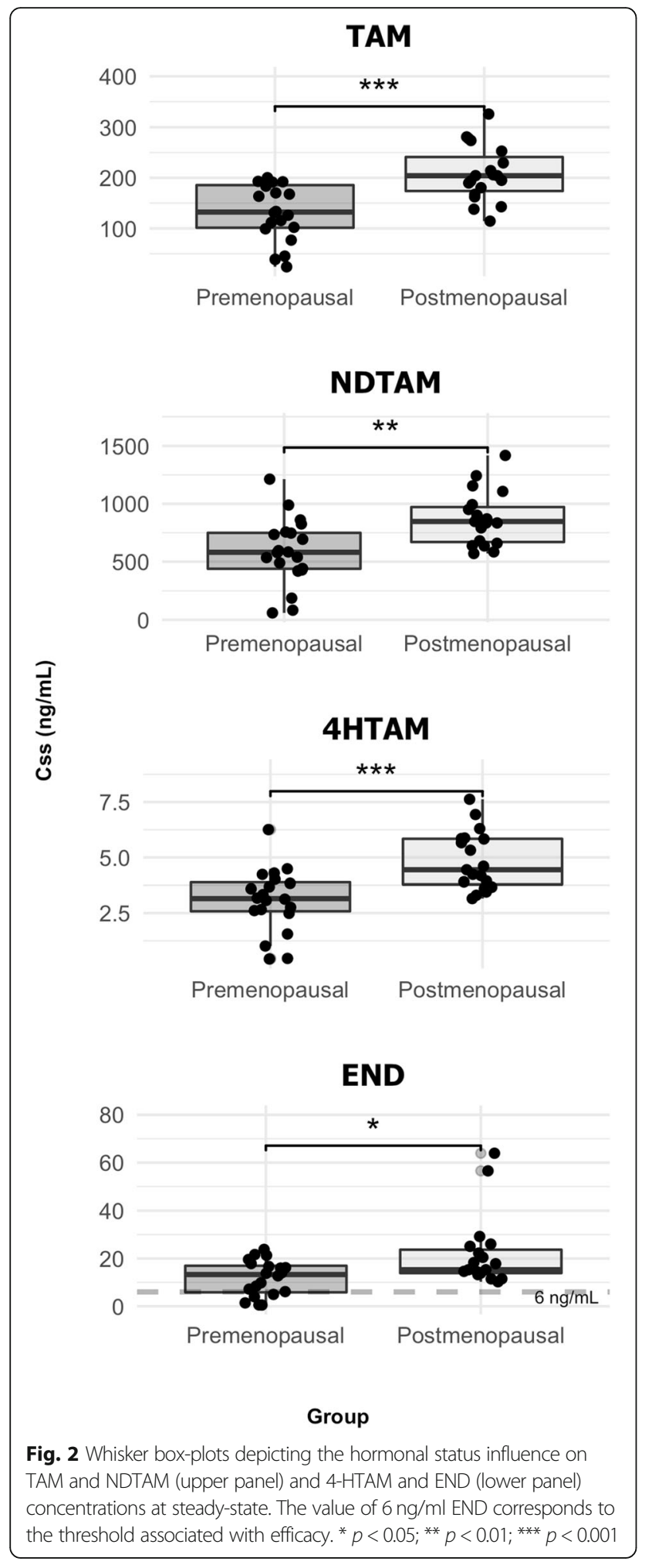

Based on a multiple regression model, the increased Css of TAM was attributed only to hormonal status, while the increased Css of END was assigned to hormonal status and race (white and non-white), while
Table 3 Frequencies of CYP2D6 and CYP3A gene variants in the investigated TAM-treated breast cancer patients $(n=40)$

\begin{tabular}{|c|c|c|c|}
\hline \multicolumn{2}{|l|}{ Gene } & $\begin{array}{l}\text { Premenopausal } \\
(n=20)\end{array}$ & $\begin{array}{l}\text { Postmenopausal } \\
(n=20)\end{array}$ \\
\hline \multicolumn{4}{|l|}{ CYP2D6 } \\
\hline Activity score & Function & \multicolumn{2}{|c|}{ Frequencies of gene variants } \\
\hline 0 & PM & 0 & 0 \\
\hline 0.5 & IM & 0.15 & 0 \\
\hline 1 & Slow NM & 0.30 & 0.2 \\
\hline 1.5 & NM & 0.25 & 0.35 \\
\hline 2 & NM & 0.25 & 0.35 \\
\hline \multirow[t]{2}{*}{$>2$} & UM & 0 & 0 \\
\hline & others & 0.05 & 0.10 \\
\hline \multicolumn{4}{|l|}{ CYP3A5 } \\
\hline \multirow[t]{4}{*}{ *3 } & Variant & & \\
\hline & $\mathrm{AA}(* 3 / * 3)$ & 0.65 & 0.7 \\
\hline & AG $\left({ }^{*} 3 / * 1\right)$ & 0.35 & 0.2 \\
\hline & $\mathrm{GG}\left(*^{*} 1 *^{*} 1\right)$ & 0 & 0.1 \\
\hline \multicolumn{4}{|l|}{ CYP3A4 } \\
\hline \multirow[t]{4}{*}{$* 1 \mathrm{~b}$} & Variant & & \\
\hline & $\mathrm{AA}\left({ }^{*} 1 /{ }^{*} 1\right)$ & 0.8 & 0.7 \\
\hline & $\mathrm{AG}\left({ }^{*} 1 /{ }^{*} 1 \mathrm{~b}\right)$ & 0.2 & 0.3 \\
\hline & $\mathrm{GG}\left({ }^{*} 1 \mathrm{~b} / *^{*} 1 \mathrm{~b}\right)$ & 0 & 0 \\
\hline \multirow[t]{4}{*}{ *22 } & Variant & & \\
\hline & CC $\left({ }^{*} 1 / *^{*} 1\right)$ & 0.9 & 0.95 \\
\hline & $\mathrm{CT}\left({ }^{*} 1 /{ }^{*} 22\right)$ & 0.1 & 0.05 \\
\hline & $\Pi(* 22 / * 22)$ & 0 & 0 \\
\hline
\end{tabular}

other demographic characteristics, such as age, were not identified as predictors.

The influence of hormonal status on TAM pharmacokinetics between the investigated groups is probably due to the differences in the bioavailability, considering that the $\mathrm{C}_{\mathrm{SS}}$ metabolic ratios TAM/NDTAM, TAM/4HTAM, and 4HTAM/END (Table 2) did not change. These results suggest that the increased $C_{S S}$ of the active metabolite END in postmenopausal patients is not due to increased CYP activity but increased TAM bioavailability. Considering that TAM and END are substrates of the efflux drug transporter P-gp [35, 36], it is reasonable to hypothesize that a lower Pgp activity in the gut of postmenopausal patients could result in increased TAM bioavailability.

The influence of hormonal status on TAM pharmacokinetics was not identified in previous studies [37-42], probably due to the lack of balance in the numbers of patients included in both the pre- and postmenopausal groups and the consequent lack of significant statistical power.

Figure 1 shows that the END steady-state plasma concentrations were above $6 \mathrm{ng} / \mathrm{mL}$ for 35 of 40 investigated 
patients. Notably, $6 \mathrm{ng}$ of $\mathrm{END} / \mathrm{mL}$ plasma is the threshold value associated with a $26 \%$ lower risk of recurrence in adjuvant breast cancer treatment [4]. However, when we analyzed the END geometric mean plasma concentrations only in the premenopausal group $(n=20)$, the observed values were too close to the threshold value of $6 \mathrm{ng} / \mathrm{mL}$. This finding is in agreement with Saldores et al. (2015) [15], who demonstrated that patients with low END plasma concentrations $(<6 \mathrm{ng} / \mathrm{mL})$ exhibited a higher risk for distant relapse or death compared with higher END plasma concentrations.

Interestingly, the final multiple regression modeling included not only the hormonal state but also race as predictors for Css of END. In our data, the investigated population was inferred to be white and non-white, with $85 \%$ white and $15 \%$ non-white premenopausal patients and $75 \%$ white and $25 \%$ non-white postmenopausal patients. END Css included race as a predictor, with a $\beta$ coef of $11.945 \pm \mathrm{SE} 2.836$. The race-associated differences may be a consequence of differences in the frequencies of genetic polymorphisms in drug metabolism and drug transporters, among other factors. This finding is in agreement with Hoffmeyer et al., 2000 [43], who showed that the C3435T SNP of ABCB1 varies among different ethnic groups and correlates with lower expression of intestinal P-gp [44].

Previous observations about the relationship between body weight and TAM metabolism are controversial [45]. Regarding the relationship between BMI and plasma exposure of TAM and its metabolites, only the NDTAM Css showed a significant correlation (Fig. 3). This is not

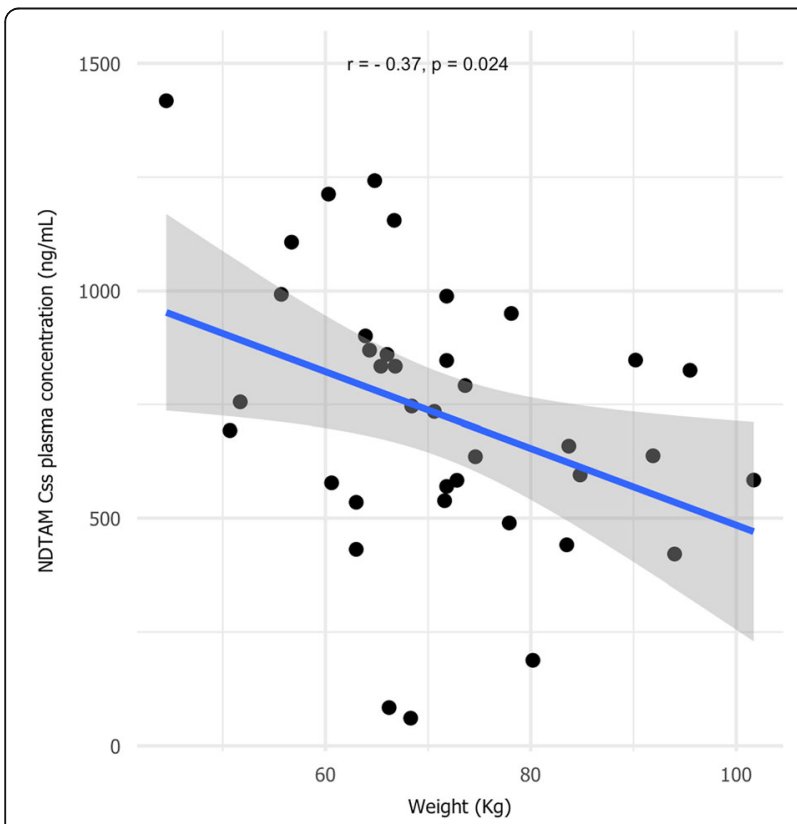

Fig. 3 Correlation between body weight and NDTAM steady-state concentrations in all investigated TAM-treated breast cancer patients $(n=40)$ surprising since NDTAM is a highly lipophilic agent and has a more prolonged half-life among the TAM metabolites [46, 47].

There were certain limitations to the present study. First, the sample size for the pharmacogenetic analysis was small. Second, a P-gp probe was lacking, and third, limited information from the clinical follow-up was available.

\section{Conclusions}

In conclusion, we identified hormonal status as an essential predictor of the pharmacokinetics of TAM and its metabolites END, 4-HTAM and NDTAM. The premenopausal status was associated with decreased END plasma concentrations by $135 \%$ compared to postmenopausal status. Thus, the END plasma concentrations should be monitored mainly in the premenopausal period to maintain plasma levels above the efficacy threshold value.

\section{Abbreviations}

4-HTAM: 4-hydroxytamoxifen; AUC: Area under the plasma concentrationtime curve from time zero to $24 \mathrm{~h}$; CL/F: Apparent clearance; Cmax: Maximum plasma concentration; Cmin: Minimum plasma concentration; Css: Concentration in the steady state; END: Endoxifen; ER: Estrogen receptor; IM: Intermediate metabolizer; MR: Metabolic ratio; NDTAM: N-desmethyltamoxifen; NM: Normal metabolizer; PM: Poor metabolizer; TAM: Tamoxifen; Tmax: Time to reach the Cmax; UM: Ultrarapid metabolizer

\section{Acknowledgments}

The authors would like to thank the São Paulo Research Foundation (FAPESP) and the Brazilian National Council for Scientific and Technological Development (CNPq) for funding support.

\section{About this supplement}

This article has been published as part of BMC Pharmacology and Toxicology Volume 20 Supplement 1, 2019: Proceedings of Toxi-Latin 2018. The full contents of the supplement are available online at https://

bmcpharmacoltoxicol.biomedcentral.com/articles/supplements/volume-20supplement-1.

\section{Authors' contributions}

JPBX and VLL performed the research proposal, conceived and designed the experiments, discussed all the results and wrote the manuscript. JMdA was the clinical trial coordinator. EBC and GSK were responsible for the genotype tests, while MPM was responsible for the LC-MS/MS analysis. All authors read and approved the final manuscript.

\section{Funding}

This publication was funded by the São Paulo Research Foundation (FAPESP).

\section{Availability of data and materials}

On reasonable request, the content is available from the corresponding author.

\section{Ethics approval and consent to participate}

The study was approved by the ethics review committees of the School of Pharmaceutical Sciences of Ribeirão Preto, University of São Paulo, SP, Brazil and of the Teaching Hospital of Ribeirão Preto Medical School, University of São Paulo, SP, Brazil (record number: 35539714.7.0000.5403). All patients provided written consent.

Consent for publication Not applicable. 


\section{Competing interests}

The authors declare that they have no competing interests.

\section{Author details}

'Department of Clinical Analysis, Toxicology and Food Science, School of Pharmaceutical Sciences of Ribeirão Preto, University of São Paulo, Ribeirão Preto, Brazil. ²Department of Gynecology and Obstetrics, Ribeirão Preto Medical School, University of São Paulo, Ribeirão Preto, Brazil. ${ }^{3}$ Department of Internal Medicine, Ribeirão Preto Medical School, University of São Paulo, Ribeirão Preto, Brazil. ${ }^{4}$ Division of Pharmacology, National Cancer Institute of Brazil, Rio de Janeiro, Brazil.

\section{Published: 19 December 2019}

\section{References}

1. Goetz MP, Sangkuhl K, Guchelaar H-J, Schwab M, Province M, Whirl-Carrillo $\mathrm{M}$, et al. Clinical Pharmacogenetics implementation consortium (CPIC) guideline for CYP2D6 and Tamoxifen therapy. Clin Pharmacol Ther. 2018; 103(5):770-7.

2. Early Breast Cancer Trialists' Collaborative Group (EBCTCG). Relevance of breast cancer hormone receptors and other factors to the efficacy of adjuvant tamoxifen: patient-level meta-analysis of randomised trials. Lancet. 2011;378(9793):771-84

3. Jordan VC, Collins MM, Rowsby L, Prestwich G. A monohydroxylated metabolite of tamoxifen with potent antioestrogenic activity. J Endocrinol. 1977;75(2):305-16

4. Madlensky L, Natarajan L, Tchu S, Pu M, Mortimer J, Flatt SW, et al. Tamoxifen metabolite concentrations, CYP2D6 genotype, and breast cancer outcomes. Clin Pharmacol Ther. 2011;89(5):718-25.

5. Desta Z, Ward BA, Soukhova NV, Flockhart DA. Comprehensive evaluation of tamoxifen sequential biotransformation by the human cytochrome P450 system in vitro: prominent roles for CYP3A and CYP2D6. J Pharmacol Exp Ther. 2004:310(3):1062-75.

6. Mürdter TE, Schroth W, Bacchus-Gerybadze L, Winter S, Heinkele G, Simon $W$, et al. Activity levels of tamoxifen metabolites at the estrogen receptor and the impact of genetic polymorphisms of phase I and II enzymes on their concentration levels in plasma. Clin Pharmacol Ther. 2011:89(5):708-17.

7. Klein DJ, Thorn CF, Desta Z, Flockhart DA, Altman RB, Klein TE. PharmGKB summary: tamoxifen pathway, pharmacokinetics. Pharmacogenet Genomics. 2013;23(11):643-7

8. Goetz MP, Rae JM, Suman VJ, Safgren SL, Ames MM, Visscher DW, et al. Pharmacogenetics of tamoxifen biotransformation is associated with clinical outcomes of efficacy and hot flashes. J Clin Oncol. 2005;23(36):9312-8.

9. Schroth W, Antoniadou L, Fritz P, Schwab M, Muerdter T, Zanger UM, et al. Breast Cancer treatment outcome with adjuvant Tamoxifen relative to patient CYP2D6 and CYP2C19 genotypes. J Clin Oncol. 2007;25(33):5187-93.

10. Schroth W, Goetz MP, Hamann U, Fasching PA, Schmidt M, Winter S, et al. Association between CYP2D6 polymorphisms and outcomes among women with early stage breast cancer treated with tamoxifen. JAMA. 2009; 302(13):1429-36.

11. Province MA, Goetz MP, Brauch H, Flockhart DA, Hebert JM, Whaley R, et al. CYP2D6 genotype and adjuvant tamoxifen: meta-analysis of heterogeneous study populations. Clin Pharmacol Ther. 2014;95(2):216-27.

12. Rae JM, Drury S, Hayes DF, Stearns V, Thibert JN, Haynes BP, et al. CYP2D6 and UGT2B7 genotype and risk of recurrence in tamoxifen-treated breast cancer patients. J Natl Cancer Inst. 2012;104(6):452-60.

13. Regan MM, Leyland-Jones B, Bouzyk M, Pagani O, Tang W, Kammler R, et al. CYP2D6 genotype and tamoxifen response in postmenopausal women with endocrine-responsive breast cancer: the breast international group 1-98 trial. J Natl Cancer Inst. 2012;104(6):441-51.

14. Goetz MP, Suman VJ, Hoskin TL, Gnant M, Filipits M, Safgren SL, et al. CYP2D6 metabolism and patient outcome in the Austrian breast and colorectal cancer study group trial (ABCSG) 8. Clin Cancer Res. 2013;19(2): 500-7.

15. Saladores P, Mürdter T, Eccles D, Chowbay B, Zgheib NK, Winter S, et al. Tamoxifen metabolism predicts drug concentrations and outcome in premenopausal patients with early breast cancer. Pharmacogenomics J. 2015;15(1):84-94

16. Maximov PY, McDaniel RE, Fernandes DJ, Korostyshevskiy VR, Bhatta P, Mürdter TE, et al. Simulation with cells in vitro of tamoxifen treatment in premenopausal breast cancer patients with different CYP2D6 genotypes. $\mathrm{Br}$ J Pharmacol. 2014:171(24):5624-35.

17. Gustavson LE, Benet LZ. Menopause: pharmacodynamics and pharmacokinetics. Exp Gerontol. 1994:29(3-4):437-44.

18. Harris RZ, Tsunoda SM, Mroczkowski P, Wong H, Benet LZ. The effects of menopause and hormone replacement therapies on prednisolone and erythromycin pharmacokinetics. Clin Pharmacol Ther. 1996;59(4):429-35.

19. Singh JC, Lichtman SM. Effect of age on drug metabolism in women with breast cancer. Expert Opin Drug Metab Toxicol. 2015;11(5):757-66.

20. Nazir S, labal Z, Nasir F. Impact of menopause on pharmacokinetics of Rosuvastatin compared with premenopausal women. Eur J Drug Metab Pharmacokinet. 2016;41(5):505-9.

21. Dowsett M, Haynes BP. Hormonal effects of aromatase inhibitors: focus on premenopausal effects and interaction with tamoxifen. J Steroid Biochem Mol Biol. 2003:86(3-5):255-63.

22. Teunissen SF, Rosing $H$, Schinkel AH, Schellens JHM, Beijnen JH. Bioanalytical methods for determination of tamoxifen and its phase I metabolites: A review. Anal Chim Acta. 2010;683(1):21-37.

23. Sohn DR, Kusaka M, Shin SG, Jang IJ, Chiba K, Ishizaki T. Utility of a one-point (3-hour postdose) plasma metabolic ratio as a phenotyping test using metoprolol in two east Asian populations. Ther Drug Monit. 1992;14(3):184-9.

24. Neves DV, Lanchote VL, de Souza L, Hayashida M, Nogueira MS, de Moraes NV, et al. Metoprolol oxidation polymorphism in Brazilian elderly cardiac patients. J Pharm Pharmacol. 2013;65(9):1347-53.

25. Jabor VAP, Coelho EB, Dos Santos NAG, Bonato PS, Lanchote VL. A highly sensitive LC-MS-MS assay for analysis of midazolam and its major metabolite in human plasma: applications to drug metabolism. J Chromatogr B Anal Technol Biomed Life Sci. 2005;822(1-2):27-32.

26. Lamba JK, Lin YS, Schuetz EG, Thummel KE. Genetic contribution to variable human CYP3A-mediated metabolism. Adv Drug Deliv Rev. 2002;54(10): 1271-94.

27. Etienne MC, Milano G, Fischel JL, Frenay M, François E, Formento JL, et al. Tamoxifen metabolism: pharmacokinetic and in vitro study. $\mathrm{Br} J$ Cancer. 1989;60(1):30-5

28. Pharmacogene Variation Consortium [Internet]. [cited 2018 May 9]. Available from: https://www.pharmvar.org/gene/CYP2D6

29. Gaedigk A, Sangkuhl K, Whirl-Carrillo M, Klein T, Steven LJ. Prediction of CYP2D6 phenotype from genotype across world populations. Genet Med. 2017:19(1):69-76.

30. Gaedigk A, Simon SD, Pearce RE, Bradford LD, Kennedy MJ, Leeder JS. The CYP2D6 activity score: translating genotype information into a qualitative measure of phenotype. Clin Pharmacol Ther. 2008;83(2):234-42.

31. Lønning PE, Lien EA, Lundgren S, Kvinnsland S. Clinical pharmacokinetics of endocrine agents used in advanced breast Cancer. Clin Pharmacokinet. 1992;22(5):327-58

32. Stearns $V$, Johnson MD, Rae JM, Morocho A, Novielli $A$, Bhargava $P$, et al. Active tamoxifen metabolite plasma concentrations after coadministration of tamoxifen and the selective serotonin reuptake inhibitor paroxetine. J Natl Cancer Inst. 2003;95(23):1758-64

33. Jin Y, Desta Z, Stearns V, Ward B, Ho H, Lee K-H, et al. CYP2D6 genotype, antidepressant use, and Tamoxifen metabolism during adjuvant breast Cancer treatment. JNCI J Natl Cancer Inst. 2005;97(1):30-9.

34. Lien EA, Anker G, Ueland PM. Pharmacokinetics of tamoxifen in premenopausal and postmenopausal women with breast cancer. J Steroid Biochem Mol Biol. 1995;55(2):229-31.

35. Rao US, Fine RL, Scarborough GA. Antiestrogens and steroid hormones: substrates of the human P-glycoprotein. Biochem Pharmacol. 1994;48(2):287-92.

36. Choi JS, Kang KW. Enhanced tamoxifen bioavailability after oral administration of tamoxifen in rats pretreated with naringin. Arch Pharm Res. 2008;31(12):1631-6.

37. Nowell SA, Ahn J, Rae JM, Scheys JO, Trovato A, Sweeney C, et al. Association of genetic variation in tamoxifen-metabolizing enzymes with overall survival and recurrence of disease in breast cancer patients. Breast Cancer Res Treat. 2005;91(3):249-58

38. Kiyotani K, Mushiroda T, Hosono N, Tsunoda T, Kubo M, Aki F, et al. Lessons for pharmacogenomics studies: association study between CYP2D6 genotype and tamoxifen response. Pharmacogenet Genomics. 2010;20(9):565-8.

39. Ramón y Cajal T, Altés A, Paré L, del Rio E, Alonso C, Barnadas A, et al. Impact of CYP2D6 polymorphisms in tamoxifen adjuvant breast cancer treatment. Breast Cancer Res Treat. 2010;119(1):33-8. 
40. Lash TL, Cronin-Fenton D, Ahern TP, Rosenberg CL, Lunetta KL, Silliman RA, et al. CYP2D6 inhibition and breast cancer recurrence in a population-based study in Denmark. J Natl Cancer Inst. 2011;103(6):489-500.

41. Wegman P, Elingarami S, Carstensen J, Stål O, Nordenskjöld B, Wingren S. Genetic variants of CYP3A5, CYP2D6, SULT1A1, UGT2B15 and tamoxifen response in postmenopausal patients with breast cancer. Breast Cancer Res. 2007;9(1):R7.

42. Wegman P, Vainikka L, Stål O, Nordenskjöld B, Skoog L, Rutqvist L-E, et al. Genotype of metabolic enzymes and the benefit of tamoxifen in postmenopausal breast cancer patients. Breast Cancer Res. 2005;7(3):R284-90.

43. Hoffmeyer S, Burk O, von Richter O, Arnold HP, Brockmöller J, Johne A, et al. Functional polymorphisms of the human multidrug-resistance gene: multiple sequence variations and correlation of one allele with $\mathrm{P}$ glycoprotein expression and activity in vivo. Proc Natl Acad Sci U S A. 2000; 97(7):3473-8.

44. Chen ML. Ethnic or racial differences revisited: impact of dosage regimen and dosage form on pharmacokinetics and pharmacodynamics. Clin Pharmacokinet. 2006;45(10):957-64.

45. MacCallum J, Cummings J, Dixon JM, Miller WR. Concentrations of tamoxifen and its major metabolites in hormone responsive and resistant breast tumours. Br J Cancer. 2000;82(10):1629-35.

46. Guerrieri-Gonzaga A, Johansson H, Bonanni B, Diani S, Decensi A, Baglietto $L$, et al. Correlation between tamoxifen elimination and biomarker recovery in a primary prevention trial. Cancer Epidemiol Biomark Prev. 2001;10(9): 967-70.

47. Lien EA, Solheim E, Ueland PM. Distribution of tamoxifen and its metabolites in rat and human tissues during steady-state treatment. Cancer Res. 1991;51(18):4837-44.

\section{Publisher's Note}

Springer Nature remains neutral with regard to jurisdictional claims in published maps and institutional affiliations.

Ready to submit your research? Choose BMC and benefit from:

- fast, convenient online submission

- thorough peer review by experienced researchers in your field

- rapid publication on acceptance

- support for research data, including large and complex data types

- gold Open Access which fosters wider collaboration and increased citations

- maximum visibility for your research: over $100 \mathrm{M}$ website views per year

At $\mathrm{BMC}$, research is always in progress.

Learn more biomedcentral.com/submissions 